\title{
Evolutionary product development as a design tool
}

\author{
Arthur O. Eger* and J.W. Drukker
}

Faculty of Engineering Technology,

University of Twente,

P.O. Box 217, 7500 AE Enschede, The Netherlands

E-mail: a.o.eger@utwente.nl

E-mail: j.w.drukker@utwente.nl

*Corresponding author

\begin{abstract}
In an earlier study, the six phases of the economic product life cycle were complemented with a set of six qualitative 'product phases', which allows us to explain in what phases of the product life cycle qualities such as functionality, ergonomics, production technology, styling, as well as the service level and the ethical behaviour of a company are important. The six product phases are called: performance, optimisation, itemisation, segmentation, individualisation and awareness. In the original study, it was proposed that the product phases follow one after another. In a follow up study, it was concluded that the last three phases often exist simultaneously. In this paper, first the results of the follow up study are summarised. After that, the results will be presented of research into if and how master students of Industrial Design Engineering were able to use the theory to create starting points for new product development.
\end{abstract}

Keywords: evolutionary product development; design; design history; design methodology; economic product life cycle; segmentation; individualisation; innovation.

Reference to this paper should be made as follows: Eger, A.O. and Drukker, J.W. (2012) 'Evolutionary product development as a design tool', J. Design Research, Vol. 10, No. 3, pp.141-154.

Biographical notes: Arthur O. Eger holds a $\mathrm{PhD}$ in Industrial Design Engineering at the TU Delft. In 2003, he became a Professor of Product Design at the University of Twente. He has a broad experience in industrial design engineering, wrote seven and edited five books, and published over 100 articles and papers. Since 2000, he is the Chief Editor of Product Magazine, a publication of MYbusinessmedia, Rotterdam. Since 2004 he is member, and since 2009 he is Chairman of the Board of the Department of Industrial Design Engineering of KIVI NIRIA, the Royal Institution of Engineers in the Netherlands.

J.W. Drukker studied quantitative economics and economic history at Erasmus University, The Netherlands, Purdue University, USA, University of Essex, UK and University of Groningen, The Netherlands. He holds a PhD in Economics (Groningen) and worked as Associate Professor of Economics and Economic History in University of Groningen (1972-2005) and Professor of Industrial Design and Design History in Delft University of Technology (1987-2007). His current affiliation is as a Professor of Design History in University of Twente since 2007. His research interests are in economic history, anthropometric history and design history. He has published regularly in all three fields. 


\section{Introduction}

It is remarkable that during the past decades, in a number of disciplines in the social and economic sciences in the formulation of theories about developments, an evolutionary starting point has taken the place of deterministic starting points. Examples are economics and economic history (Nelson and Winter, 1982; Freeman and Louçã, 2001), in the closely to economics related research after technologic developments (Ziman, 2000), in psychology (Gaulin and McBurney, 2004) and in cultural change processes (McDonald Dunbar and Knight, 1999). In a review of the literature on product development decisions Krishnan and Ulrich (2001) conclude that " $(\ldots)$ there is essentially no academic research on industrial design, the activity largely concerned with the form and style of products. Yet aesthetic design may be one of the most important factors in explaining consumer preference in some product markets, including automobiles, small appliances, and furniture" [Krishnan and Ulrich, (2001), p.14]. An exhaustive overview of these aspects (aesthetic, semantic and symbolic aspects of design) is given by Crilly et al. (2004). Some conclusions of this overview match with the theory presented in this paper. They mention the appearance after some time of a dominant design (that they call a 'stereotype' or 'prototype' and they agree with our conclusion that in mature markets performance of products is taken for granted so that attention of the design has to shift to 'emotional benefits'. They state in their overview that "(...) very few of the scientific studies have led to generalisations which are useful for students or practitioners of design" [Crilly et al., (2004), p.559]. The methods and techniques that industrial designers have at their disposal and that are helpful with their design task, seem for a large part to rely on experience and intuition. In an earlier study (Eger, 2007; Eger and Drukker, 2010; Figure 1), it was shown that this way of working, however seemingly intuitive, nonetheless displays certain regularities that can be generalised into a model of six consecutive qualitative product phases, in which each phase can be described by means of ten product characteristics. Generally speaking, products will follow these product phases in the same order. The aim of the model is to improve insight into a product's life cycle.

Figure 1 The six product phases from the first study (see online version for colours)

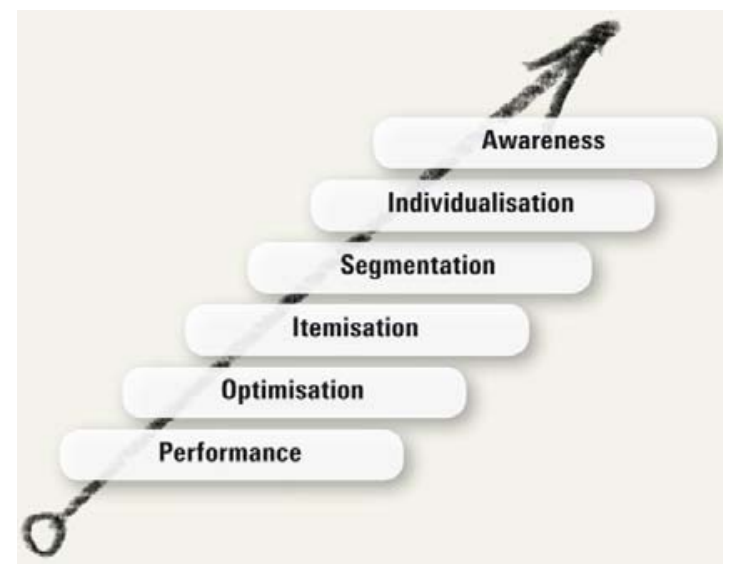




\subsection{Further research}

In the previously mentioned study (Eger, 2007), five recommendations for future research were given:

1 analyse more products (than the five done in the study of 2007)

2 investigate to what extend the theory also holds for immaterial products (services) ${ }^{1}$

3 research the similarities and possible differences between consumer products (BtoC) and business to business (BtoB) products

4 research to what degree the last two product phases form a part of the segmentation phase, or whether they should be considered as separate product phases

5 find out to what extent designers are able to make 'correct predictions about future products' based on the theory of product phases.

In a follow up study (Eger and Drukker, in press; Figure 2), the results of a further investigation of points 1 and 4, above, were presented. This article reports on the analysis of over 70 products. Based on this research, a number of improvements of the original model were proposed. The results of this study will be described in the following section. After that, an elaboration of point 5, that is the subject of this paper, will be presented. The paper ends with plans for future research, regarding the five questions.

Figure 2 Improved model of the product phases (see online version for colours)

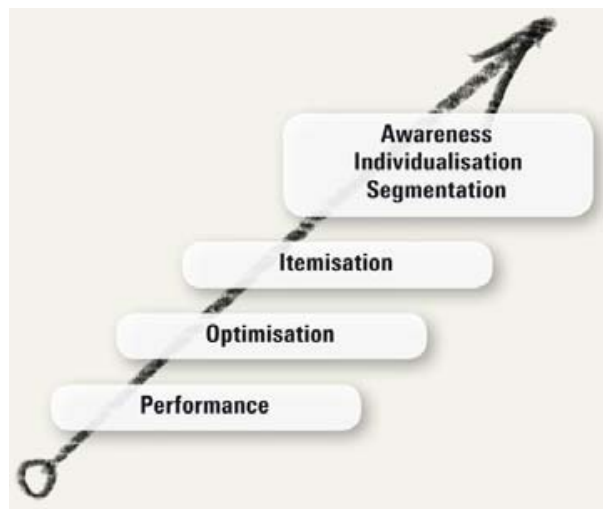

Note: The last three product phases occur simultaneously.

\subsection{How product phases can map the status quo of a product}

Introducing product phases opens up the possibility to analyse the relationships between the different fields of industrial design engineering: ergonomics, marketing, construction and styling. The form giving of a product can be analysed in relation to its (primary and secondary) functionality, its ergonomic qualities, its production technology and its possibilities to offer emotional benefits. To demonstrate this, six qualitative product phases are proposed: performance, optimisation, itemisation, segmentation, individualisation, and awareness. Placed in chronological order, a more or less general pattern reveals itself, which enables - to some extent - the possibility of 
explaining a product's development. Each product phase can be described in terms of eight product characteristics of which four apply to the product itself; and the others to its market, its production technology, the services that accompany the product and the ethical aspects of the product in question. The eight product characteristics that we propose are $^{2}$ :

1 newness

2 functionality

3 product development

4 styling

5 pricing

6 production

7 service

8 ethics.

\section{Characteristics of the product phases}

We state that each of the six product phases displays a typical pattern of product characteristics. In this section, these product characteristics will be made explicit for each product phase.

\subsection{Performance}

New products - that is: products based on new technologies - normally suffer from teething troubles for some time when they have been put on the market. By implication, improvement of primary functionality (i.e., the technical performance of the product) is the most important aspect of product development in this phase. Technically, new products often start as status symbols, and usually perform worse than the existing alternatives. The product characteristics of the product phase 'performance' can be summarised as follows. The product is technically speaking new and results from a 'technology push'. The performance of the product is often poor. Product development is primarily aimed at improving the performance. Design in the limited sense of 'overall form giving' is unimportant, and therefore, product aesthetics are of minor concern. Often the product is put on the market by a monopolist or a small number of heterogeneous oligopolists, so price competition is low. As a consequence, the price per unit can be relatively high. The product is frequently produced by standard machinery equipment; it often has more parts than the number that would be technically feasible, and assembly is mostly done by hand.

\subsection{Optimisation}

In the second phase, product development is broadened to include ergonomic aspects and issues of reliability in use and safety. The product phase 'optimisation' is characterised as follows. Although the product is technically speaking still new, consumer awareness of the product starts to develop. The performance of the product is reasonable, but product 
development is still aimed at improving performance. Other aspects, like increased reliability, improvement of aspects of ergonomics and safety are becoming serious considerations. The price per unit is still relatively high, but increasing competition creates a tendency towards lower prices. In this phase - and in the following - it can be advantageous to involve clients in the product development process to improve the performance and ergonomics.

\subsection{Itemisation}

When producers have improved their product to the point that they satisfy generally accepted standards of functionality and reliability, the edge of competition shifts to convenience. Buyers will prefer those products that are the most convenient to use and - especially in the BtoB market - sellers that are convenient to deal with. With mass produced products, personal selling becomes impossible. The growth of the market becomes less and the number of competitors increases. As the product range grows, prices fall and promotion costs increase. An endeavour sets in to develop extra features and accessories, including special editions of the product that are developed for different trade channels and target groups. Design becomes more important, and product aesthetics become a major concern. The number of product parts of the basic (cheapest) products decreases, but accessories or extra features can cause an opposite effect: an increase of the number of parts. Mechanic and/or automatic assembly becomes more important. If needed, well-organised service organisations are set up to support the product.

\subsection{Segmentation, individualisation and awareness}

In the original study, based on five retrospective case studies and a classification by experts, it was proposed that the product phases follow one another, although in the conclusions and recommendations some questions were put with this result. Based on the additional study (Eger and Drukker, in press) it can be concluded that the last three phases often exist simultaneously, and that sometimes one or two of these phases are not suited for the product or product group.

\subsection{Segmentation}

In the first three product phases (i.e., performance, optimisation and itemisation) the focus was on improved functionality, reliability, ergonomics and safety. An endeavour to add extra features and accessories in order to differentiate the product from its competitors, sets in somewhere in the third stage. However, possibilities of differentiation are limited, due to technical restraints, price considerations and usability. Actually, it occurs more often than not that during the overall improvement pattern of a product, a stage is reached where performance offered is apparently more than performance required. For relatively uncomplicated products, such as furniture and trinkets, the possibilities to add features or accessories are limited. Moreover, for innovators and early adopters, products become less attractive during the latter product phases. The market share is such, that the product can be considered to be 'accepted'. Owning the product is no longer distinctive, as it does not offer any form of status. Adding emotional benefits to a product is now a possibility. Recent research (Candi et al., 2010) has shown that designers should play a significant role here, because Candi et al. found that involving 
customers when designing emotional benefits (experience design) does not improve the success of the product. Where involving customers in the first three phases does improve the success, in this phase it does not. A possible explanation may be that these customers are too much focused on the functionality of the product.

Characteristics of the product phase 'segmentation' are: almost all members of the target group know the product from their own experience or have at least heard of it. As the product, technically speaking, enters the domain of some 'dominant design' (or, a limited number of 'dominant designs'), product development is aimed at adding extra features and accessories, including special editions of the product for different trade channels and target groups. Design has reached a stage of complete integration of the different parts of the product into a completely unified and recognisable form and design focus shifts from form giving proper to expressive features, aimed at increasing emotional benefits. The market approaches perfect competition.

\subsection{Individualisation}

Extrapolation of segmentation (continuous fine tuning of products on ever smaller target groups) ultimately leads to a product well tuned upon one individual. Recent developments in information and production technology make this kind of individualisation even more possible. These developments imply the following changes in characteristics in the product phase 'individualisation'. Product development is geared to mass customisation and co-creation, allowing the customer to influence the final result. The market starts to shift from a homogeneous polypoly into a heterogeneous polypoly. Although prices approach average technical production costs of the dominant design, co-creation and mass customisation offer possibilities to realise higher prices. Interactive media are used to customise the product to the needs of the individual customer.

\subsection{Awareness}

A substantial part of the consumers is willing to contribute to a better environment and to help solving societal problems by changing their consumption patterns, but only if this can be done without much effort, and only if it does not lead to decrease of consumer satisfaction and to an increase in financial burden. Most people do expect companies to play an active role in solving common societal problems. A company can successfully tempt consumers - especially those who are committed to purchasing luxury products - by offering them the possibility to show their ethical involvement by acquiring products that claim in some way to be more environmentally or socially beneficial than their competitors. This leads to slight changes in the characteristics of the last product phase, 'awareness'. The addition of extra features and accessories, including special editions of the product for different trade channels and target groups, has not stopped, but becomes of secondary concern. Design is focused upon the enhancement of expressive features, aimed at increasing emotional benefits, but when these benefits start to include ethical concerns, this can lead to a sudden leap into ascetic and sober forms. This tendency is reinforced even more by product claims on societal and environmental issues. The producing company explicitly communicates company ethics in its promotion campaigns. The ethical behaviour of the producing company does influence - to some extent - consumers' choices. The company can for instance be successful with products that become more attractive during use ('positive aging') (Eger and Drukker, in press). 


\section{To what extent can designers use the model when designing new products?}

The research question attended in this paper is whether the model of product phases can be helpful in predicting the most probable future development of a product, in other words, does the model offer designers starting points when they are developing new products? Do designers consider these starting points too rigid or does the model leave too much design freedom? In the next section, the following questions will be addressed:

5 Find out to what extent designers are able to make 'correct predictions about future products' based on the theory of product phases.

This main question can be divided into the following sub-questions:

5a Is the model a useful tool in the first phase of the design process, when the product and the market are analysed?

$5 \mathrm{~b}$ Does it offer starting points for a redesign?

5c Can it give directions regarding functionality or styling of a product?

$5 \mathrm{~d}$ Does it leave enough design freedom for the designer or do designers consider the starting points too rigid? (On the delicate balance between 'enough freedom' and 'too much rigidity', see: Conclusions.)

To find an answer to these questions, designs that were made with the aid of the theory by students of Industrial Design Engineering at the University of Twente, were analysed.

\subsection{Working method}

The results presented in this section are based on the work of 81 students of the master course Evolutionary Product Development. ${ }^{3}$ These students created redesigns for 73 products, guided by the model of the product phases. (Eight products were worked on twice.) The instructions to the students were to study and analyse the history of a product of their choice, and to create a new design for this product, both by applying the model of product phases. The designs were created between 2005 and 2008 (Figure 3), in which period the course was given three times.

Figure 3 The 73 products that were redesigned by master students

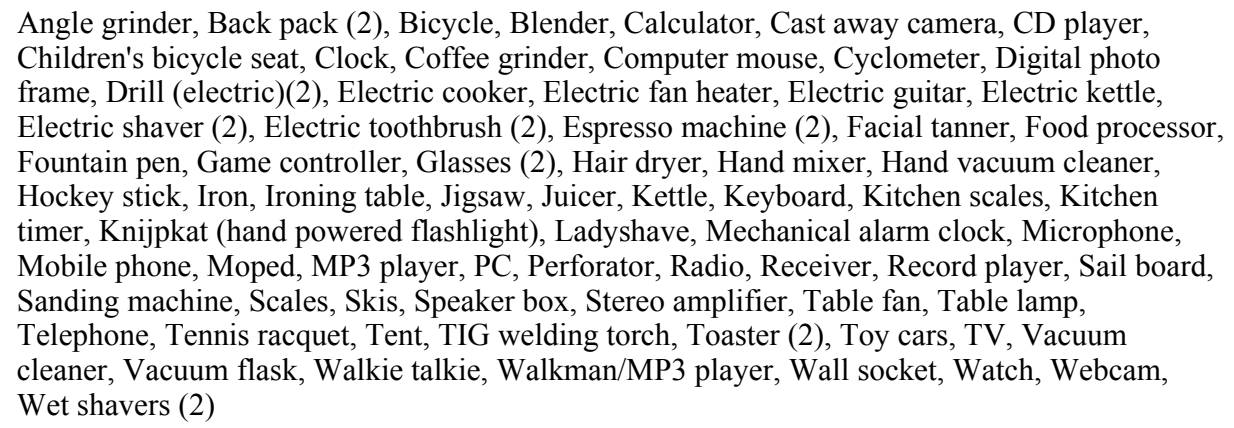

Note: Between parentheses indicates the number of times the product was chosen. 


\subsection{Examples}

To illustrate the results of the students, four designs were selected. The first three examples show how the theory can give direction to the design process. The fourth project gives an example of how and why three of the students decided to deviate from the model. The examples were also chosen because they give an example of products in the product phases that most of the students concluded that their product could be found: segmentation, individualisation and awareness.

\section{Example 1: moped}

\section{Student: Victor van Eekelen}

van Eekelen (2005) determined that the moped is in the individualisation phase. It is possible to have a moped custom made to a great extent (mass customisation) and there are many accessories on the market that people can assemble themselves. He also concludes that the market in the Netherlands mainly consists of youth in the age between 16 and 18, which are not very sensitive for the ethic aspects of the mopeds or their manufacturers. He therefore chose to try to design a moped that can be positioned in the awareness phase, aimed at a somewhat older target group, but styled in a way that the moped is also attractive for younger people. He chose this design direction because he believes that there are no mopeds aimed at this target group. Aspects he added to his design that should make his product attractive for this group are: an economical four stroke engine, an exhaust pipe with attenuation and filters, and steel parts because they are stronger, easier to repair and better to recycle (Figure 4).

Figure 4 Redesign of a moped in the awareness phase (see online version for colours)

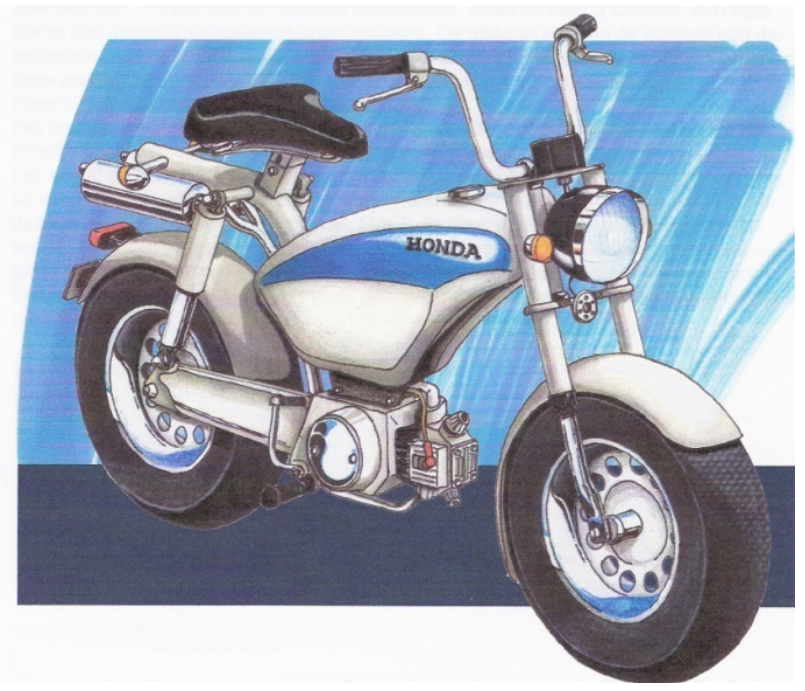

Source: van Eekelen (2005) 


\section{Example 2: bicycle}

\section{Student: Koen van der Wal}

van der Wal (2005) believes the bicycle to be in both the individualisation phase and the awareness phase. Since halfway through the eighties of the last century in Belgium and the Netherlands it is possible to have your own bicycle custom built. Bicycles entered the awareness phase somewhere around 1980, but for slightly different reasons than the theory of product phases predicts. In this period, the bicycle is rediscovered as a healthy and environmentally friendly alternative to the 'unhealthy and polluting' car. However, these qualities were not deliberately developed by manufacturers, for instance by using environmentally friendly materials and production processes or by committing themselves to social responsibility. These qualities were simply inherent to the product itself since its incubence and would have come to the surface anyway, even if manufacturers had no environmental conscientiousness at all. van der Wal chose to further investigate the individualisation phase because he sees chances for an interactive website that makes it possible for consumers to design their own bicycle. His website offers consumers a number of fixed positions (saddle, handle-bar, crankshaft and front crutch) between which they can design their own frame. Examples of pages of his website can be found in Figure 5.

Figure 5 Website to design your own bicycle (individualisation phase) (see online version for colours)

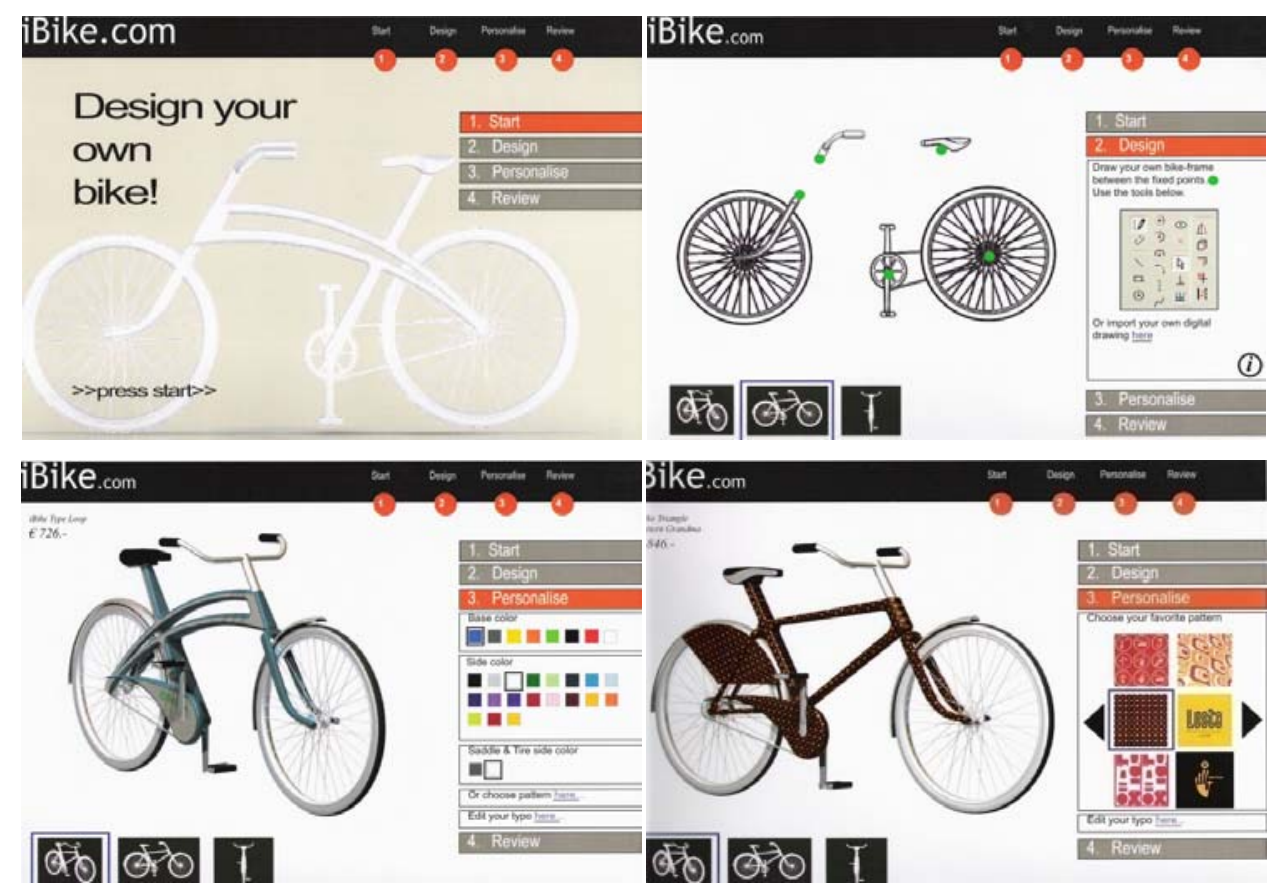

Source: van der Wal (2005) 


\section{Example 3: toaster}

\section{Student: Ruud Elders}

According to Elders (2006) the toaster is in the segmentation phase and he argues that it is very likely that the product will stay there. The need to individualise the product is, according to him, non-existent. The simplicity and long product life do not offer many chances for a design aimed at the awareness phase. He therefore chose a target group that he describes with the following keywords: young, single, trendy, dynamic, hurried, career oriented. With regard to the use moment he chose breakfast. Because of this target group the toaster must be suited for new and bigger kinds of bread, with thicknesses up to one inch. His design is depicted in Figure 6.

Figure 6 Redesign of a toaster in the segmentation phase (see online version for colours)
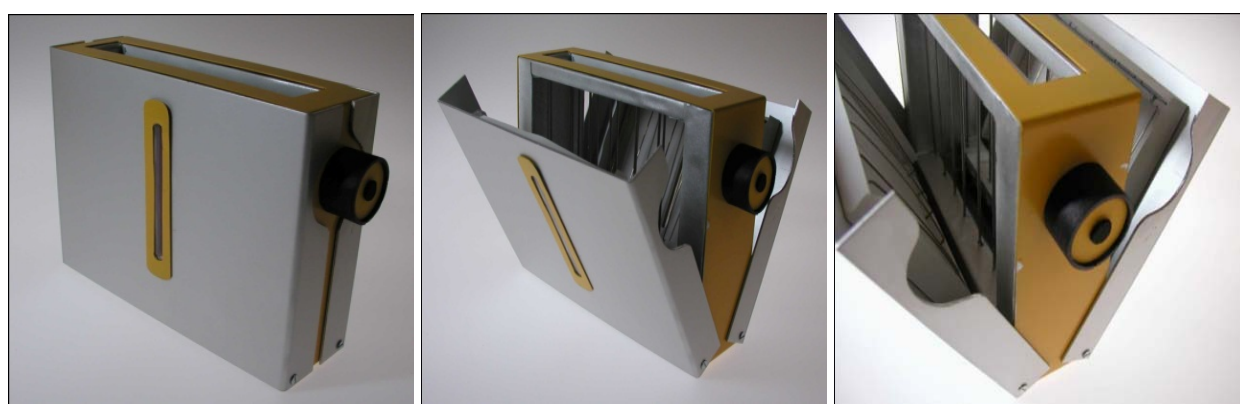

Source: Elders (2006)

Figure 7 Redesign of a clock in the awareness phase (see online version for colours)
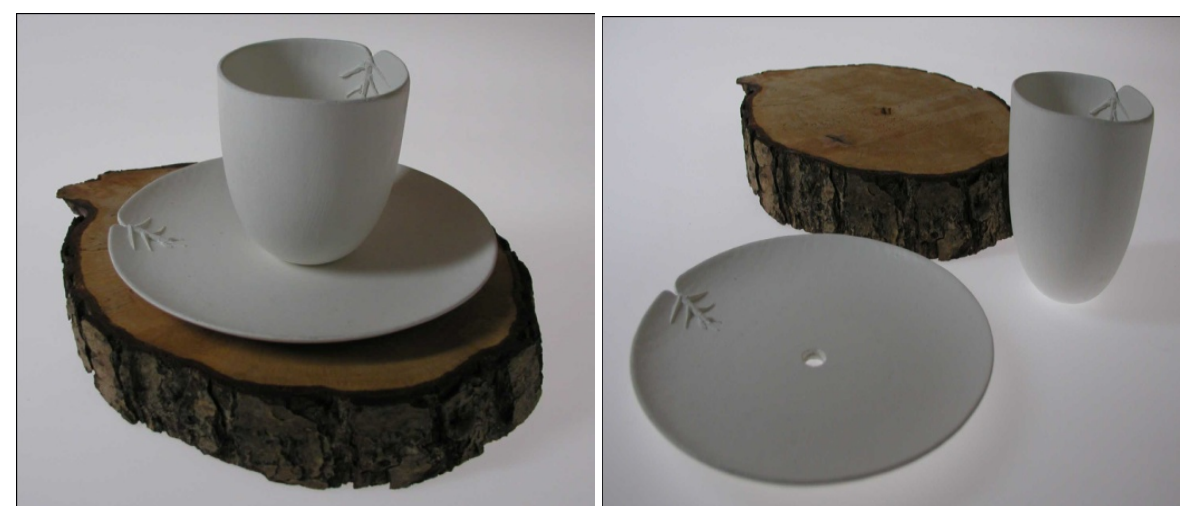

Source: Geraedts (2006)

\section{Example 4: clock}

Student: Vincent Geraedts

The segmentation of the clock is such - there is so much choice - that, according to Geraedts (2006), there is no need for individualisation. "Time is very important (...) The 24 hours economy runs at full speed (...) Time is dominant (...) The consequence is that 
time dictates peoples' lives (...) A half hour of extra time is sometimes considered as a precious gift." He therefore chose to make his design of a clock to be a statement on how time rules our lives. His design, called tea-time, is a clock that 'does not want to be a clock'. The cup and saucer of the clock form the hour- and minute-hands of the clock. When using the clock, by drinking tea from one of the 'hands', time is, so to speak, brought to a standstill (Figure 7).

\section{Conclusions}

Master students that participated in the course Evolutionary Product Development were very well able to develop a new version of an existing product. When using the model, most of them found good starting points, both in the theory and in what their research into the history of the product produced. Remarkable is that the students nearly all chose BtoC and that they found that - according to their research - the products were all in the segmentation phase or in one of the two next phases (Table 1). The only BtoB product that was chosen, was the TIG welding torch which was, according to the researcher, in the itemisation phase. In only three cases, the students decided not to follow the theory. One of them can be found in the previous section: the clock. The other two were the facial tanner and the pocket calculator. From the research of the history of the product it proved that the facial tanner was at the end of its economic life cycle. The student therefore decided to develop a new product (in the performance phase) aimed as much as possible at the same target group. In the second example, it proved that a calculator function nowadays can be found in a lot of products, such as mobile phones, PDAs, and laptops. The pocket calculator is only used as a present given to business acquaintances. Based on this finding, the student decided to make use of a completely new technique for his calculator: micro liquid technique. With that he also chose the performance phase (Table 2).

Table 1 Present product phase of the researched products according to the master students

\begin{tabular}{lc}
\hline Performance & 0 \\
Optimisation & 0 \\
Itemisation & 1 \\
Segmentation & 63 \\
Individualisation & 12 \\
Awareness & 5 \\
Total & 81 \\
\hline
\end{tabular}

Table 2 Product phases considered by the students for the redesign of the chosen product

\begin{tabular}{lc}
\hline Performance & 2 \\
Optimisation & 0 \\
Itemisation & 0 \\
Segmentation & 80 \\
Individualisation & 51 \\
Awareness & 54 \\
\hline
\end{tabular}


The four sub-questions were:

5a Is the model a useful tool in the first phase of the design process, when the product and the market are analysed?

5 b Does it offer starting points for a redesign?

5c Can it give directions regarding functionality or styling of a product?

$5 d$ Does it leave enough design freedom for the designer or do designers consider the starting points too rigid?

In general it can be concluded that the theory offers a useful tool in the first steps of a new product development project: the analysis phase, where existing, competing products are studied with regard to their functionality, ergonomics, safety and marketing (sub-question 5a); and in the phase where ideas are generated for the preliminary design (sub-questions $5 \mathrm{~b}$ and $5 \mathrm{c}$ ). On the other hand the theory does always offer several options, never only one; and these options are not very detailed, leaving a lot of room for the designer to choose and detail the chosen concept. The question is whether it is desirable to offer more detail or is the remaining design freedom an advantage of the model? It is very well possible that this differs per individual (sub-question $5 \mathrm{~d}$ ).

\subsection{Bottlenecks for the students}

Some of the students used the theory too rigidly (sub-question $5 \mathrm{~d}$ ). If the theory predicts that the next step is individualisation, they decide that the new product has to be positioned in this phase, without critically considering if the product offers enough possibilities to do so and if there is a target group that is interested in the proposed concept.

Table 3 Product phases chosen by the students for the redesign

\begin{tabular}{lcc}
\hline Present product phase & No. & For redesign chosen product phase \\
\hline Itemisation & 1 & Segmentation \\
& 0 & Individualisation \\
Segmentation & 0 & Awareness \\
& 2 & Performance \\
& 42 & Segmentation \\
Individualisation & 16 & Individualisation \\
& 3 & Awareness \\
& 4 & Segmentation \\
Awareness & 4 & Individualisation \\
& 4 & Awareness \\
& 3 & Segmentation \\
& 2 & Individualisation \\
\end{tabular}

Notes: Left column: present product phase of the analysed product

Right column: product phase that was chosen

Middle column: No. $=$ number of times the product phase mentioned in the right column was chosen 
The assignment in the course stated that the students were supposed to take a small, evolutionary step in their design process. A small number of the students had problems with this part of the assignment and tried to make a revolutionary leap, for instance by choosing a completely new technique or completely new materials (sub-question $5 \mathrm{~d}$ ). Some students, who had chosen a product in the segmentation phase, had doubts if the product would ever reach one of the next phases. Their considerations, written down in their reports, contributed to the conclusion that the last three phases often co-exist, mentioned in the first section of this paper, and published in more detail in Eger and Drukker (in press). Table 3 gives an overview of the phases where the products were, according to the students, and the phases where the redesign of the students was positioned.

\subsection{Recommendations and further research}

An important aspect of research question five was if designers are able to do 'correct predictions about future products'. Because the designers were students and their products will therefore not be brought to the market, it is not possible to draw conclusions with regard to this part of the question. However, at this moment Vermeulen (2009) is carrying out a PhD-research at the University of Twente called 'An Innovation Tool for the $\mathrm{SME}^{4}$, where it is the intention to develop products with the aid of the model, that will actually be brought to the market. We hope and expect that with the results of this research some answers to this question can be given. Another important aspect of this research is that there will be more BtoB products considered in this research. Finally, the question arose if the theory can offer more detailed starting points for product development. This question will hopefully come to the front in another $\mathrm{PhD}$ research by Ehlhardt (in press). Drawing from an archive with over five decades product test reviews published by the Dutch consumer organisation 'Consumentenbond' the history of products and their selling arguments will be analysed based on developments in, and differences between products tested by this organisation over the years. Special attention will be given to the changes in the aspects of the products that were tested over the years.

\section{References}

Candi, M., Gemser, G., and Van den Ende, J. (2010) Effectiviteit van Design, RSM, Erasmus University, Rotterdam.

Crilly, N., Moultrie, J. and Clarkson, J. (2004) 'Seeing things: consumer response to the visual domain in product design', Design Studies, November, Vol. 25, No. 6, pp.547-577.

Eger, A.O. (2007) Evolutionary Product Development: How 'Product Phases' Can Map The Status Quo and Future of a Product, Lemma Publishers, Den Haag.

Eger, A.O. and Drukker, J.W. (2010) 'Phases of product development: a qualitative complement to the product life cycle', Design Issues, Vol. 26, No. 2, pp.47-58.

Eger, A.O. and Drukker, J.W. (in press) 'Product development: an evolutionary model', Eleven International Publishing, The Hague, The Netherlands.

Ehlhardt, H. (in press) 'Child restraint systems, an analysis of their development from an evolutionary perspective', Eleven International Publishing, The Hague, The Netherlands.

Elders, R.G. (2006) 'De ontwikkeling van de toaster - productfasen', Unpublished thesis, University of Twente, Enschede. 
Freeman, C. and Louçã, F. (2001) As Time Goes by: from the Industrial Revolutions to the Information Revolution, Oxford University Press, Oxford.

Gaulin, S.J.C. and McBurney, D.H. (2004) Evolutionary Psycholgy, 2nd ed., Prentice Hall, Upper Saddle River, NJ.

Geraedts, V.P.J. (2006) 'De klok', Unpublished thesis, University of Twente, Enschede.

Krishnan, V. and Ulrich, K.T. (2001) 'Product development decisions: a review of the literature', Management Science, January, Vol. 47, No. 1, pp.1-21.

McDonald Dunbar, R.I. and Knight, C.D. (1999) The Evolution of Culture: An Interdisciplinary View, Edinburgh University Press, Edinburgh.

Nelson, R.R. and Winter, S.G. (1982) An Evolutionary Theory of Economic Change, Belknap Press of Harvard University Press, Cambridge (Mass.).

van der Wal, K. (2005) 'Productfasen Fiets; Onderzoek \& Ontwerp', Unpublished thesis, University of Twente, Enschede.

van Eekelen, V.J.J.J. (2005) 'Van Solex tot scooter; productfasen van de bromfiets', Unpublished thesis, University of Twente, Enschede.

Vermeulen, F.G.A. (2009) 'Innoveren of Sterven', BNO Vormberichten, June, No. 6.

Ziman, J. (Ed.) (2000) Technological Innovation as an Evolutionary Process, Cambridge University Press, Cambridge.

\section{Notes}

1 In the study of 2007 only one of the retrospective case studies was about services (holidays).

2 In the original study (Eger, 2007) ten product characteristics were proposed. In the study by Eger and Drukker (in press) two of them turned out to be statistically insignificant. However, both of them are more or less exogeneous to designers. One of them, the number of competitors, is usually a given fact. The second, the way promotion is done, is in most cases not or only partially influenced by designers.

3 This research is based on the work that was done by students that participated in the master course Evolutionary Product Development. This course is part of the two years master programme Industrial Design Engineering at the University of Twente. In the first part of the course, the history of a chosen product is studied with the theory of product phases in mind. An existing product is analysed. An example of the product has to be bought and is dismantled as part of the assignments of the course. Special attention is paid to the production methods used (forming, separating and joining processes), use of materials, surface textures (coatings) and product arrangement or assemblies. In the second part of the course, a redesign is made for the product. This design has to be a possible 'next logic step' (of course there are always several possibilities) based on the theory of product phases.

$4 \quad$ Small and medium sized enterprises. 